\title{
Prognosis of Oligodendroglioma Patients Stratified by Age: A SEER Population-Based Analysis
}

\author{
Kai Jin \\ Shu-Yuan Zhang \\ Li-Wen Li \\ Yang-Fan Zou \\ Bin Wu \\ Liang Xia \\ Cai-Xing Sun
}

Department of Neurosurgery, The Cancer Hospital of the University of Chinese Academy of Sciences (Zhejiang Cancer Hospital), Institute of Basic Medicine and Cancer (IBMC), Chinese Academy of Sciences, Hangzhou,

Zhejiang, People's Republic of China
Correspondence: Cai-Xing Sun Department of Neurosurgery, Zhejiang Cancer Hospital, I I th Floor, Building 2, Hangzhou City, Zhejiang Province,

People's Republic of China

Tel +86 572-88128082

Email18744016937@I63.com
Purpose: Glioma may affect patients of any age. So far, only a limited number of big data studies have been conducted concerning oligodendroglioma (OG) in diverse age groups. This study evaluated the risk factors for OG in different age groups using the Surveillance, Epidemiology, and End Results (SEER) database built by the National Cancer Institute, which is part of the National Institutes of Health.

Patients and Methods: A total of 5437 cases within the SEER database were included. These patients were divided into seven age groups. The Kaplan-Meier method was employed for survival analysis. The independent risk factors for the survival of OG patients were identified using the Cox regression model. A nomogram was drawn with $\mathrm{R}$ software based on the independent risk factors. The X-tile software was adopted to find the optimal age group at diagnosis.

Results: The all-cause mortality and the tumor-specific mortality increased with age. The univariate analysis showed that the patients' age, gender, primary lesion location, side affected by the primary lesion (left or right), surgery for the primary lesion, and tumor size were correlated with survival $(\mathrm{P}<0.05)$. Multivariate Cox regression analysis showed that age was an independent risk factor for the survival of $\mathrm{OG}$ patients $(\mathrm{P}<0.05)$. The optimal cutoff value of age in terms of overall survival (OS) and cause-specific survival (CSS) were identified as 48 and 61 years and 48 and 59 years, respectively.

Conclusion: The older the age, the worse the survival would be. That's, the mortality increased with age. In the clinic, healthcare professionals should be fully aware of the variability in the prognosis of OG patients in different age groups. Therefore, individualized treatments are recommended to $\mathrm{OG}$ patients in different age groups to optimize the prognosis.

Keywords: oligodendroglioma, SEER, age, prognosis, all-cause mortality, tumor-specific mortality

\section{Introduction}

Oligodendroglioma (OG) is a rare tumor in the central nervous system. In 1929, the name of oligodendroglioma was first proposed by Bailey and Bucy due to its appearance similarity with oligodendrocytes under the microscope. With an annual incidence of 1$2 / 1,000,000$ cases, OG accounts for about $5 \%$ of all primary brain tumors. ${ }^{1}$ OG usually affects the deep subcortical structures in the cerebral hemisphere, and the supratentorial region and frontal lobes are most common. New-onset epilepsy is the most frequent clinical manifestation of OG. ${ }^{2,3}$ Upon CT scans, OG lesions show hypodensities with calcification and sometimes with cystic changes and bleeding. The lesions may show hypointensities on T1-weighted MRI images and hyperintensities on T2-weighted MRI images. The histological diagnostic criteria for OG include uniform round and deeply 
stained nuclei surrounded by clear cytoplasm (ie, fried egg appearance), with a branched capillary network. OG was once diagnosed by the histological appearance alone. In 2016, the new WHO classification of tumors incorporated the molecular typing of OG, which further divides OG into isocitrate dehydrogenase (IDH) 1 and IDH2 mutations, $1 \mathrm{p} / 19 \mathrm{q}$ codeletion, and no special type. OG with $1 \mathrm{p} / 19 \mathrm{q}$ codeletion and IDH1 mutation is associated with better prognosis than the common type, and the efficacy of radiotherapy is favorable., Nowadays, the role of the microenvironment in low grade glioma tumor was become more and more important. ${ }^{6}$ The tumour microenvironment is made up of numerous cell types: (i) tissue-resident cells such as neurons and astrocytes; (ii) myeloid cells such as resident microglia; (iii) bone marrowderived macrophages, bone marrow-derived DCs and neutrophils; (iv) other immune cells as lymphoid cells; (v) endothelial cells, pericytes, and fifibroblasts. All these cells are surrounded by a distinctive extra-cellular matrix. For example, CD11a operates to regulate microglia migration and NF1-OPG growth factor production to generate a supportive LGG microenvironment, providing novel insight into the role microglia cells play in LGG tumor development. ${ }^{7}$

OG may affect patients of any age, but it is more likely to affect those aged 40-50 years and young adults are rarely affected. OG is the third most common primary brain tumor after glioblastoma and diffuse astrocytoma. Little is still known about OG, and the death risk of this disease can be hardly predicted. Many studies have been conducted on the risk factors for the prognosis of OG patients, which have revolutionized the treatment regimens for OG. However, little is known about the role of each risk factor in the development of this disease. Population-based studies have shown that the incidence of glioma varies across different age groups. Lowgrade glioma is a common brain tumor found in children, while high-grade glioma is most frequently present in adults. Some achievements have been made concerning the role of age in glioma patients. However, only a limited number of big data studies have been conducted concerning OG in diverse age groups. This study evaluated the risk factors for $\mathrm{OG}$ in different age groups using the SEER database built by the National Cancer Institute as part of the National Institutes of Health.

\section{Materials and Methods}

\section{Data Sources and Selection Criteria}

All data were extracted from the SEER database using the SEER*Stat software (version 8.3.9). The SEER database is an authoritative source for cancer statistics in the United
States, covering the incidence of cancers and demographic statistics, socioeconomic status, and survival of cancer patients. This database has been used in many highquality studies in the cancer field. The data source used in the present study was the latest data (2000-2018) submitted to the SEER database in November 2020. We extracted the cases that were pathologically diagnosed with GO in the brain and other neural systems from 2000 to 2018. The patient data included age, race, gender, tumor size, survival status, cause of death, survival (months), primary lesion location, and surgery for the primary lesion.

Inclusion criteria: Histologically diagnosed with OG (ICDO-3=9450/9451; Oligodendroglioma, NOS, anaplastic).

Exclusion criteria: (1) Not the first-onset of OG or the only primary disease; (2) The survival time was less than one month or entirely unknown; (3) the patient data and follow-up data were incomplete.

\section{Variables and Results}

The variables included age, race, gender, tumor size, survival status, tumor-related death, survival (months), primary lesion location, and surgery for primary lesions. These patients were divided into seven age groups, namely, 0-17, 18-30, $31-40,41-50,51-60,61-74$, and above 75 . Subgroup analysis was conducted by age, gender, and surgery for the primary lesion. Survival analysis was carried out, including all-cause mortality and tumor-specific mortality.

\section{Statistical Method}

SPSS 22.0 software was used for statistical analysis. The baseline characteristics of patients across different age groups were compared using the $\mathrm{C} 2$ test and Fisher's test. In univariate analysis, the Kaplan-Meier method was performed for survival analysis under each risk factor. The Log rank test was used for intergroup comparison. The risk factors for prognosis were analyzed using the univariate Cox regression model. For multivariate analysis, the independent risk factors for the survival of OG patients were identified using the Cox regression model. A nomogram was drawn with $\mathrm{R}$ software ( $\mathrm{R}$ version 4.0.5) based on the independent risk factors.

Finally, X-tile software was adopted to divide the patients into three subgroups (low-, medium- and highrisk groups) by age. The ages of patients were stratified using the X-tile software (version 3.6.1; Yale University, New Haven, CT, USA), which was initially developed to determine the optimal cutoff values of variables for patients with breast cancer. 


\section{Results}

\section{Baseline Characteristics of the Patients}

A total of 5437 eligible OG patients were recruited (Figure 1). There were 219 patients aged $0-17$ years, 810 patients aged 18-30 years, 1277 patients aged $31-40$ years,
1393 patients aged $41-50$ years, 1030 patients aged 51-60 years, 584 patients aged 61-74 years, and 124 patients aged 75 years and above. The patient data, including race, gender, primary lesion location, laterality (left or right), surgery, and tumor size are summarized in Table 1.

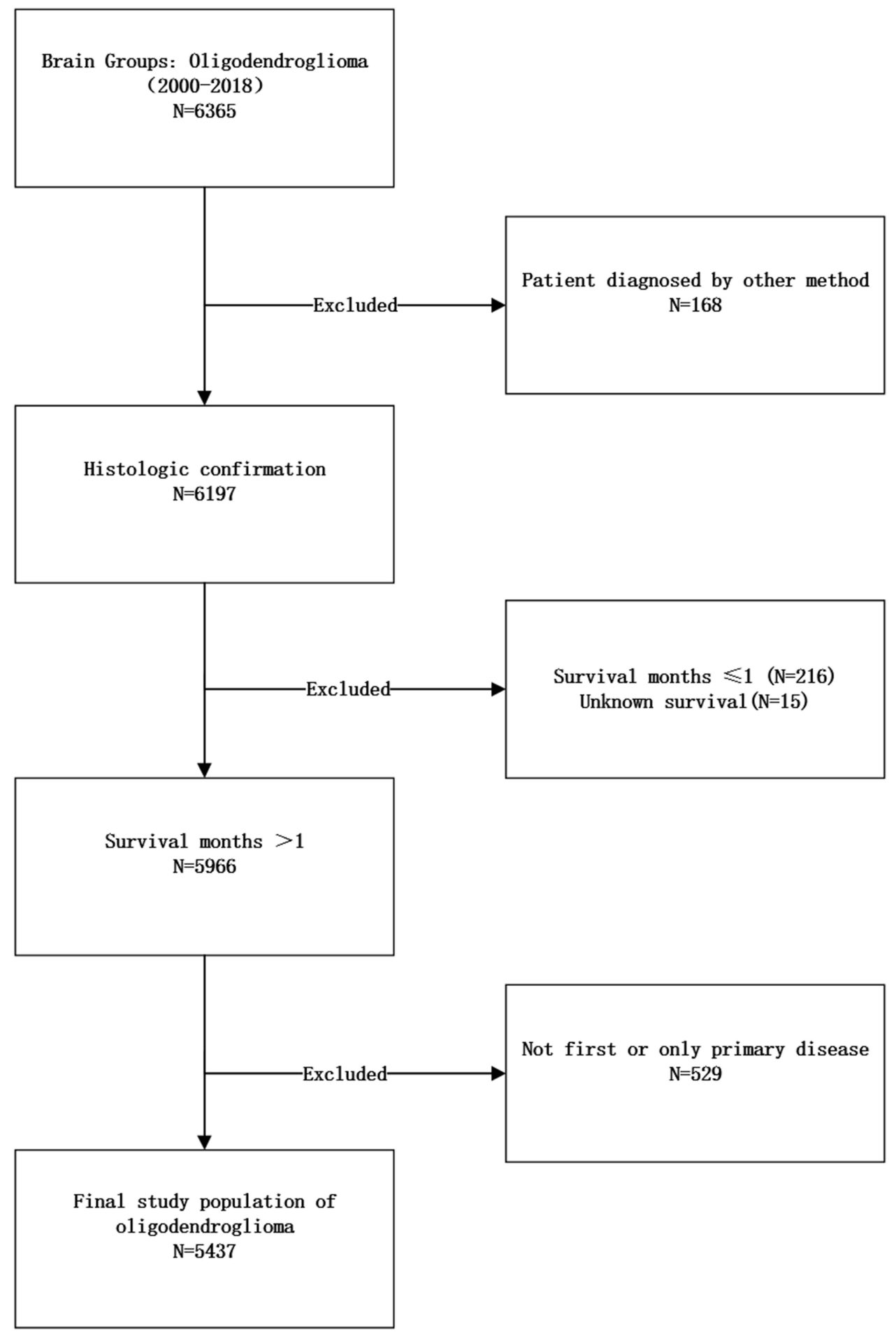

Figure I Flowchart of patient selection. Detailed selection of OG patients in 2000-2018 from SEER database. 


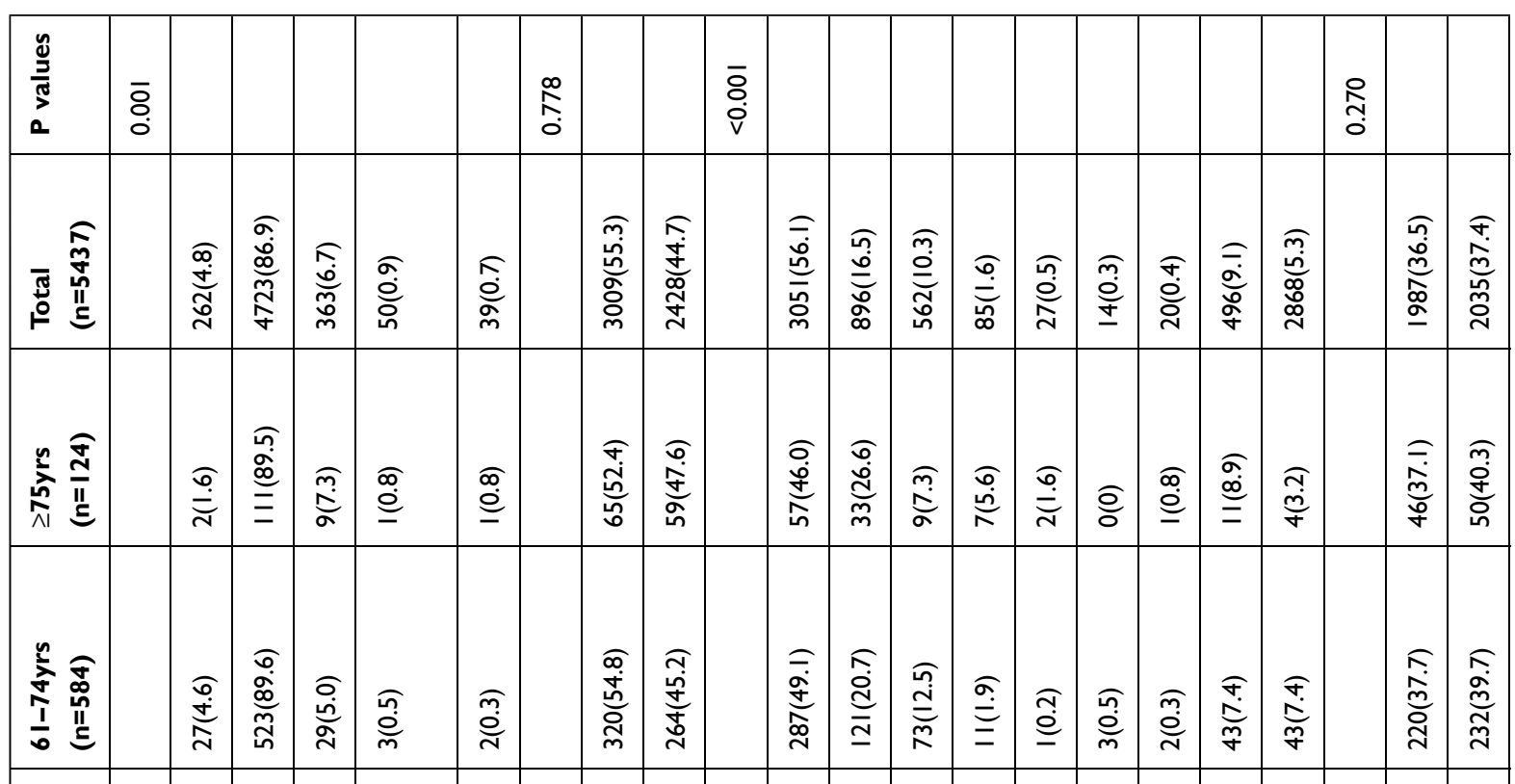

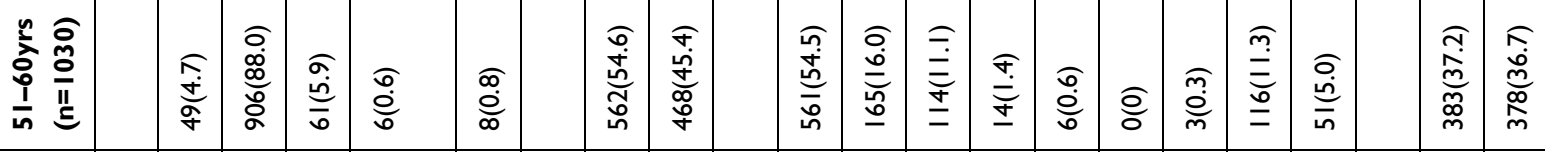

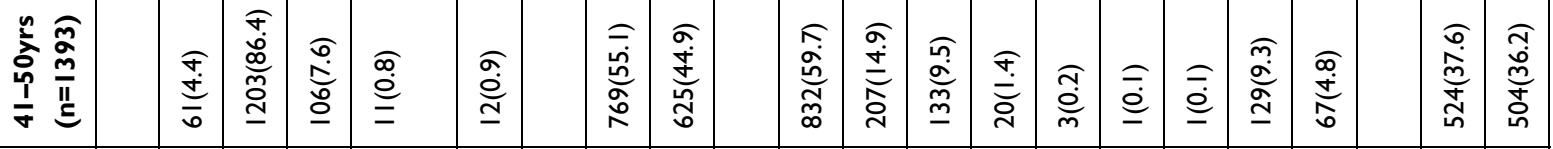

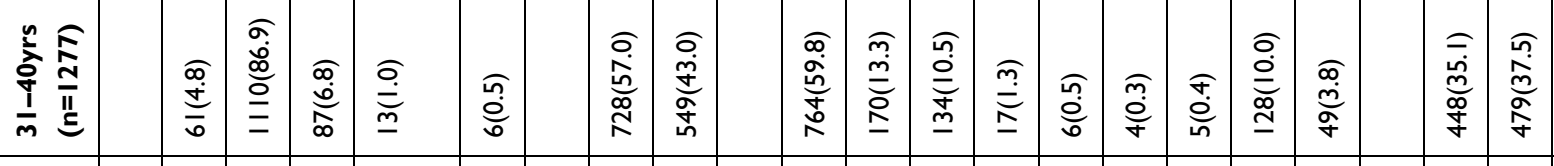

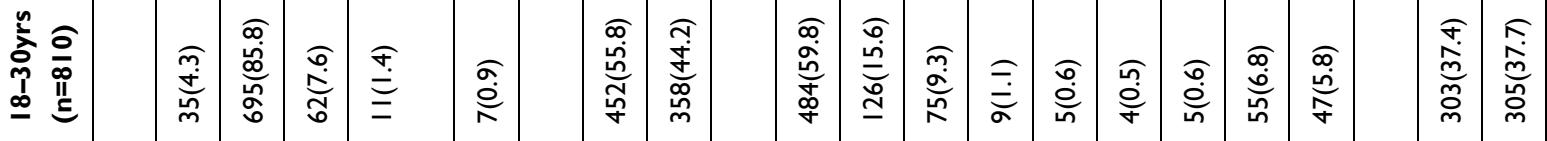

\begin{tabular}{|c|c|c|c|c|c|c|c|c|c|c|c|c|c|c|c|c|c|c|c|c|c|c|}
\hline $\begin{array}{l}\frac{n}{\grave{2}} \\
\frac{\sigma}{\pi} \\
\frac{\pi}{0}\end{array}$ & & 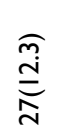 & 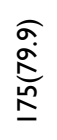 & $\widehat{\overline{\dot{\Xi}}}$ & $\underset{\widetilde{n}}{\stackrel{\sim}{n}}$ & $\underset{\text { fo }}{\stackrel{\sigma}{E}}$ & & $\begin{array}{l}\widehat{\overline{\mathrm{i}}} \\
\stackrel{\underline{\underline{S}}}{=} \\
\underline{\underline{y}}\end{array}$ & 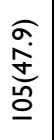 & & $\begin{array}{l}\widehat{\overline{0}} \\
\overline{0} \\
\stackrel{0}{\circ}\end{array}$ & $\begin{array}{l}\widehat{0} \\
\stackrel{n}{0} \\
\stackrel{N}{N}\end{array}$ & 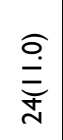 & 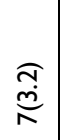 & 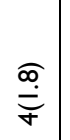 & 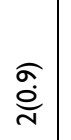 & 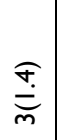 & $\begin{array}{l}\widehat{\vec{\gamma}} \\
\dot{v} \\
\underline{y}\end{array}$ & 㞼 & & 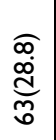 & 廅 \\
\hline 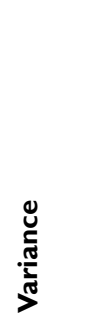 & 怤 & $\begin{array}{l}\frac{\check{y}}{\bar{\omega}} \\
\frac{\mathbb{d}}{2}\end{array}$ & 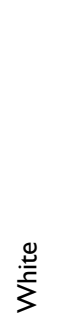 & 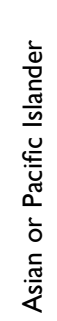 & 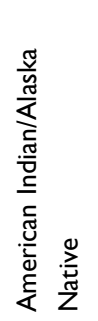 & $\begin{array}{l}\frac{3}{0} \\
\frac{5}{5} \\
\frac{5}{5}\end{array}$ & ڤ̊ & $\frac{\frac{\omega}{\pi}}{\frac{\pi}{\tilde{N}}}$ & 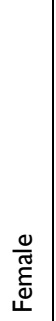 & 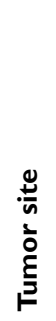 & 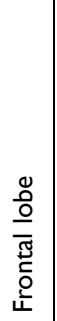 & 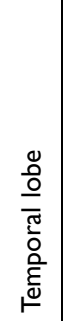 & 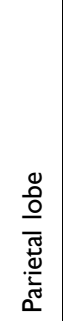 & 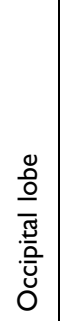 & 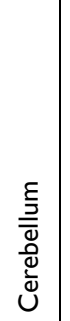 & 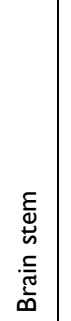 & 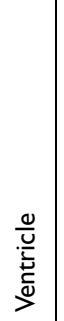 & 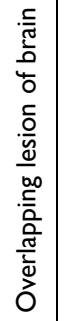 & $\begin{array}{l}\frac{n}{0} \\
\frac{0}{\tilde{c}} \\
0\end{array}$ & 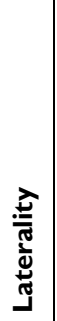 & $\stackrel{\sqcup}{\Xi}$ & $\frac{\overrightarrow{\underline{v}}}{\frac{\vec{b}}{\alpha \underline{\alpha}}}$ \\
\hline
\end{tabular}




\begin{tabular}{|c|c|c|c|c|c|c|c|c|c|c|c|c|c|}
\hline & $\begin{array}{l}\overline{8} \\
\text { ì }\end{array}$ & & & & & 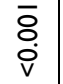 & & & & $\begin{array}{l}\overline{8} \\
\dot{i} \\
\mathrm{v}\end{array}$ & & & \\
\hline 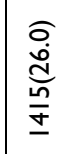 & & 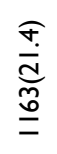 & 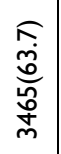 & $\stackrel{\overparen{f}}{\stackrel{\overparen{D}}{\circ}}$ & 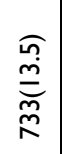 & & 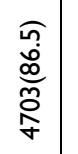 & $\begin{array}{c}\widehat{\bar{m}} \\
\stackrel{\vec{g}}{\frac{\sigma}{N}}\end{array}$ & శ્. & & 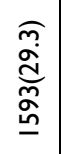 & 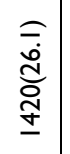 & $\begin{array}{l}\widehat{O} \\
\underset{+}{+} \\
\underset{⿱}{\mathbb{J}}\end{array}$ \\
\hline 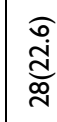 & & $\begin{array}{l}\widehat{\bar{\sigma}} \\
\stackrel{0}{\circ}\end{array}$ & 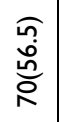 & $\begin{array}{l}\widehat{\infty} \\
\stackrel{\varrho}{=}\end{array}$ & 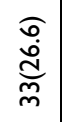 & & 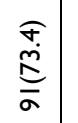 & 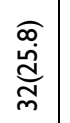 & $\stackrel{\widehat{o}}{\stackrel{0}{\varrho}}$ & & $\begin{array}{l}\text { ồ } \\
\text { ờ } \\
\text { in }\end{array}$ & 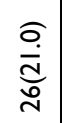 & $\begin{array}{c}\underset{\infty}{\infty} \\
\underset{\infty}{\infty} \\
\stackrel{\infty}{+}\end{array}$ \\
\hline 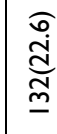 & & 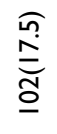 & 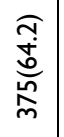 & $\underset{\infty}{\stackrel{\widehat{J}}{\dot{t}}}$ & $\begin{array}{l}\stackrel{0}{ٍ} \\
\stackrel{\equiv}{\sigma}\end{array}$ & & 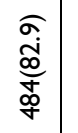 & 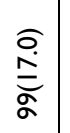 & 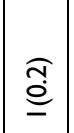 & & 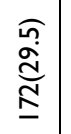 & 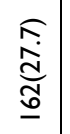 & 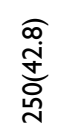 \\
\hline $\begin{array}{l}\widehat{\overline{\dot{d}}} \\
\text { dूd } \\
\text { dे }\end{array}$ & & 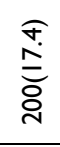 & \begin{tabular}{l}
$\widehat{\widehat{J}}$ \\
: \\
\multirow{0}{0}{} \\
0 \\
0
\end{tabular} & $\underset{\text { ọ }}{\stackrel{\Xi}{0}}$ & 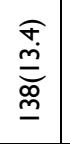 & & 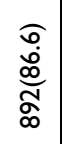 & 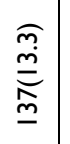 & $\widehat{\overline{0}}$ & & 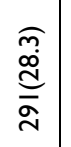 & 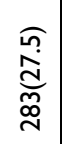 & 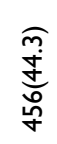 \\
\hline 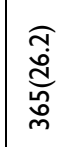 & & 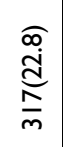 & 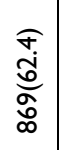 & 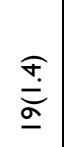 & $\begin{array}{l}\widehat{\bigcap} \\
\stackrel{m}{\infty} \\
\stackrel{\infty}{\infty} \\
\underline{\infty}\end{array}$ & & $\begin{array}{l}0 \\
\stackrel{0}{0} \\
\infty \\
\stackrel{0}{0} \\
\underline{\underline{I}}\end{array}$ & $\stackrel{\widehat{\overline{\dot{m}}}}{\stackrel{\underline{m}}{\underline{m}}}$ & $\stackrel{\widehat{m}}{\stackrel{q}{q}}$ & & 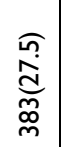 & 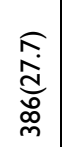 & 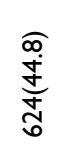 \\
\hline 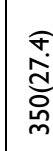 & & 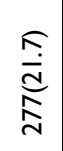 & 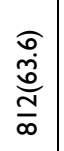 & 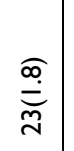 & 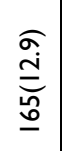 & & $\begin{array}{l}\underline{a} \\
\hat{\infty} \\
\underline{\Xi} \\
\underline{\Xi}\end{array}$ & 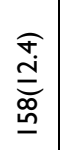 & $\stackrel{0}{\circ}$ & & 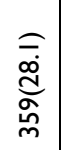 & 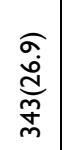 & 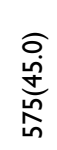 \\
\hline 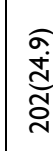 & & 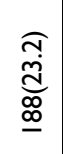 & $\begin{array}{c}\widehat{\overline{\dot{d}}} \\
\frac{\sigma}{\omega}\end{array}$ & $\underset{\underline{\underline{m}}}{\stackrel{\widehat{p}}{\dot{m}}}$ & $\begin{array}{l}\overline{\bar{\Xi}} \\
\stackrel{\bar{\Xi}}{2}\end{array}$ & & $\begin{array}{l}\widehat{a} \\
\infty \\
\infty \\
o \\
\sigma \\
\stackrel{0}{n}\end{array}$ & $\begin{array}{l}\stackrel{0}{0} \\
\stackrel{0}{0} \\
\stackrel{\infty}{0}\end{array}$ & 仓ั0 & & 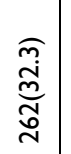 & $\begin{array}{l}\widehat{\overline{\dot{d}}} \\
\underline{\underline{\alpha}} \\
\underline{\underline{n}}\end{array}$ & 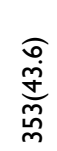 \\
\hline$\frac{\frac{\pi}{n}}{\text { ga }}$ & & 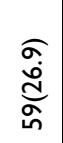 & 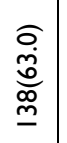 & $\begin{array}{l}\hat{\sigma} \\
\stackrel{\rho}{\rho}\end{array}$ & $\widehat{\bar{a}}$ & & $\begin{array}{l}\frac{\tilde{m}}{\dot{a}} \\
\frac{\sigma}{\grave{a}} \\
\end{array}$ & $\begin{array}{l}\underset{\sigma}{\infty} \\
\stackrel{\infty}{\sigma}\end{array}$ & $\widehat{\varrho}$ & & 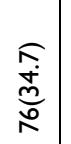 & 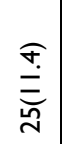 & $\begin{array}{l}\sigma \\
\tilde{n} \\
\hat{\omega} \\
\underline{\underline{\omega}} \\
=\end{array}$ \\
\hline $\begin{array}{l}3 \\
0 \\
\frac{3}{5} \\
\text { J }\end{array}$ & 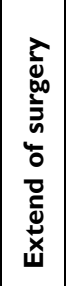 & 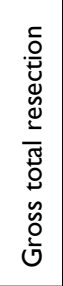 & 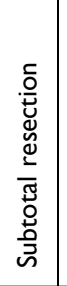 & 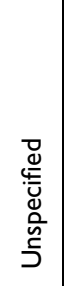 & 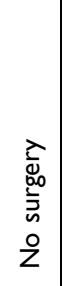 & 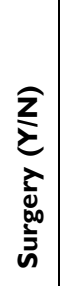 & $\stackrel{\Xi}{\check{\nu}}$ & $\stackrel{\circ}{z}$ & $\begin{array}{l}3 \\
0 \\
\frac{5}{5} \\
\frac{5}{5}\end{array}$ & 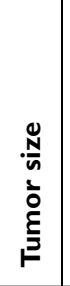 & $\begin{array}{l}\varepsilon \\
\varepsilon \\
o \\
\dot{f} \\
v \mid\end{array}$ & $\begin{array}{l}\varepsilon \\
\underline{J} \\
\stackrel{+}{\Lambda} \\
\dot{\Lambda}\end{array}$ & $\begin{array}{l}3 \\
0 \\
\frac{0}{5} \\
\frac{5}{5}\end{array}$ \\
\hline
\end{tabular}




\section{Influence of Age on All-Cause Mortality and Tumor-Specific Mortality}

Kaplan-Meier curves showed that both the all-cause mortality and tumor-specific mortality increased with age (Figure 2). In addition to age, the univariate analysis showed that gender, primary lesion location, side affected by the primary lesion (left or right), surgery for the primary lesion, and tumor size were also correlated with survival (all-cause mortality and tumor-specific mortality) $(\mathrm{P}<0.05)$. These variables were further included in the Cox regression analysis, and the results showed that gender, primary lesion location, laterality (left or right), and tumor size were all independent risk factors for survival $(\mathrm{P}<0.05)$ (Tables 2 and 3).

\section{Nomogram for Predicting OS and CSS of OG Patients}

Nomogram is widely used to predict prognosis of cancer patients because it can reduce statistical predictive models into a single numerical estimate of the probability of an event, such as death or recurrence, which is tailored to the profile of an individual patient. The nomogram was comprised of five variables above in the training set. The detailed steps for the application of the nomogram were as follows: a vertical line was drawn to the horizontal axis marked "points" at the top of the nomogram according to the classification (eg, sex was divided into male and female) of each prognostic variable (age, sex, tumor site, laterality, and tumor size). At the position where the vertical line passed through the "Points" axis, each prognostic variable was given a score. The scores of the five variables were added for the total score, the position of the total score on the horizontal axis marked as "total points" was found, and a vertical line from the total score position marked on the horizontal axis of "Total Points" was drawn to the 5-, 10and 15-year OS axis. Where the vertical line intersected the 5 -year OS axis was the 5-year overall survival rate (Figure 3).

\section{X-Tile Analysis Determined the Best Cut-off Value for the Age}

$\mathrm{X}$-tile software was used to investigate the association between patients' age and risk of mortality. The plots were created by dividing age into three populations, randomly: low, middle and high. All possible cut-off points were assessed. The brightest pixel (indicated by the black/ white circle on the $\chi^{2}$ high/low axis) denoted the optimal cut-off point. As a result, the optimal cutoff value of age in terms of overall survival (OS) was identified as 48 and 61 years, and survival curves were plotted using the KaplanMeier method for those age subgroups for OS (Figure 4A); Meanwhile, the optimal cutoff value of age in terms of cause-specific survival (CSS) was identified as 48 and 59 years, and survival curves were plotted using the KaplanMeier method for those age subgroups for CSS (Figure 4B).

\section{Discussion}

Although many studies are associated with OG, there are no novel findings concerning the prognostic factors of $\mathrm{OG}$ due to its low incidence. To our knowledge, no researchers have used a large-scale database for an independent analysis of the prognostic difference in OG patients in different age groups. Clinical and biological data have demonstrated that adults and children are significantly different in the features and outcomes of malignant

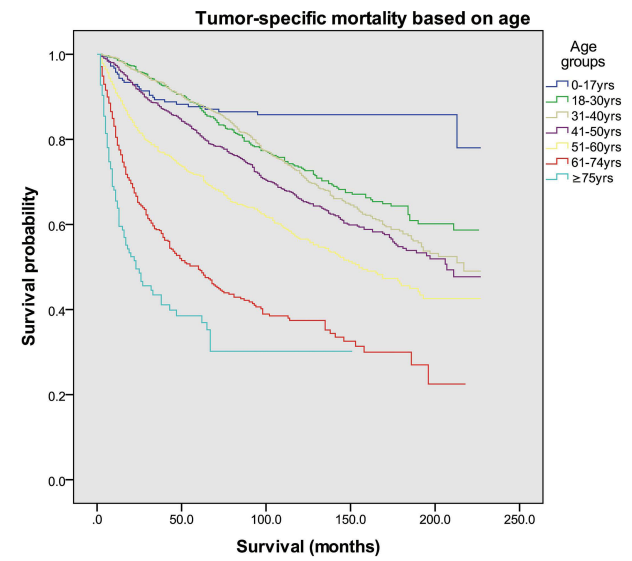

Figure 2 All-cause mortality and tumor-specific mortality based on age upon diagnosis. The difference between the curves was statistically significant according to the Log rank test $(p<0.00 I)$. 
Table 2 Univariate and Multivariate Cox Regression Analysis of Factors Associated with OS in the Training Set $(\mathrm{n}=5437)$

\begin{tabular}{|c|c|c|c|c|c|c|c|}
\hline \multirow[t]{2}{*}{ Variance } & \multirow[t]{2}{*}{ Median SurvivalıSD (Months) } & \multicolumn{3}{|c|}{ Univariate Analysis } & \multicolumn{3}{|c|}{ Multivariate Analysis } \\
\hline & & $P$ value & HR & $95 \% \mathrm{Cl}$ & $P$ value & HR & $95 \% \mathrm{Cl}$ \\
\hline Race & & 0.046 & 0.899 & $0.810-0.998$ & & & \\
\hline Black & $|47.0 \pm| 4.579$ & & & & & & \\
\hline White & $164.0 \pm 4.990$ & & & & & & \\
\hline Asian or Pacific Islander & $|8| .0 \pm 16.773$ & & & & & & \\
\hline American Indian/Alaska Native & $134.0 \pm 32.663$ & & & & & & \\
\hline \multicolumn{8}{|l|}{ Unknow } \\
\hline Sex & & 0.001 & 0.859 & $0.786-0.939$ & & & \\
\hline Male & $|5| .0 \pm 6.043$ & & & & Reference & & \\
\hline Female & $178.0 \pm 8.628$ & & & & $<0.001$ & 0.848 & $0.776-0.927$ \\
\hline Age & & $<0.001$ & 1.531 & $1.48-1.584$ & $<0.001$ & & \\
\hline $0-17 y r s$ & & & & & Reference & & \\
\hline $18-30 y r s$ & & & & & $<0.001$ & 2.340 & $1.610-3.401$ \\
\hline $31-40 y r s$ & $|97.0 \pm 7.93|$ & & & & $<0.001$ & 2.601 & $1.808-3.740$ \\
\hline $4 I-50 y r s$ & $175.0 \pm 9.232$ & & & & $<0.001$ & 3.429 & $2.391-4.917$ \\
\hline $51-60 y r s$ & $|26.0 \pm 7.04|$ & & & & $<0.001$ & 5.101 & $3.555-7.321$ \\
\hline $6 \mathrm{I}-74 y \mathrm{ys}$ & $46.0 \pm 4.931$ & & & & $<0.001$ & 10.742 & $7.461-15.467$ \\
\hline$\geq 75 y r s$ & $19.0 \pm 3.306$ & & & & $<0.001$ & 23.135 & I 5.479-34.579 \\
\hline Tumor site & & $<0.001$ & 1.082 & $1.066-1.099$ & $<0.001$ & & \\
\hline Frontal lobe & $185.0 \pm 6.470$ & & & & Reference & & \\
\hline Temporal lobe & $|28.0 \pm||| \mid 7$. & & & & $<0.001$ & 1.542 & $1.370-1.736$ \\
\hline Parietal lobe & $169.0 \pm 11.597$ & & & & 0.003 & 1.256 & $1.079-1.462$ \\
\hline Occipital lobe & 182.0 & & & & 0.337 & 1.178 & $0.843-1.647$ \\
\hline Cerebellum & & & & & 0.573 & 0.806 & $0.382-1.703$ \\
\hline Brain stem & $54.0 \pm 13.096$ & & & & 0.007 & 2.530 & $1.293-4.950$ \\
\hline Ventricle & $|27.0 \pm 63.93|$ & & & & 0.005 & 2.432 & $|.299-4.55|$ \\
\hline Overlapping lesion of brain & $109.0 \pm 7.389$ & & & & $<0.001$ & 1.611 & $1.391-1.866$ \\
\hline Others & $118.0 \pm 22.415$ & & & & $<0.001$ & $\mathrm{I} .843$ & $1.528-2.223$ \\
\hline Laterality & & $<0.001$ & 1.158 & $1.096-1.224$ & $<0.001$ & & \\
\hline Left & 170.0 & & & & Reference & & \\
\hline Right & $179.0 \pm 8.352$ & & & & 0.414 & 1.048 & $0.936-1.174$ \\
\hline Unknow & $134.0 \pm 8.644$ & & & & $<0.001$ & 1.362 & I.199-1.546 \\
\hline Extend of surgery & & $<0.001$ & 1.172 & $1.121-1.226$ & 0.346 & & \\
\hline
\end{tabular}


Table 2 (Continued).

\begin{tabular}{|c|c|c|c|c|c|c|c|}
\hline \multirow[t]{2}{*}{ Variance } & \multirow[t]{2}{*}{ Median Survival $\pm S D$ (Months) } & \multicolumn{3}{|c|}{ Univariate Analysis } & \multicolumn{3}{|c|}{ Multivariate Analysis } \\
\hline & & $P$ value & HR & $95 \% \mathrm{Cl}$ & $P$ value & HR & $95 \% \mathrm{Cl}$ \\
\hline Gross total resection & 206.0 & & & & Reference & & \\
\hline Subtotal resection & $|54.0 \pm 5.79|$ & & & & 0.100 & 1.096 & $0.983-1.222$ \\
\hline Unspecified & $|54.0 \pm||.44|$ & & & & 0.769 & 0.945 & $0.650-1.375$ \\
\hline No surgery & $124.0 \pm 8.874$ & & & & $0.67 I$ & 0.805 & $0.296-2.188$ \\
\hline Surgery $(\mathbf{Y} / \mathbf{N})$ & & $<0.001$ & 1.402 & $1.257-1.563$ & 0.671 & & \\
\hline Yes & $174.0 \pm 5.207$ & & & & Reference & & \\
\hline No & $|24.0 \pm 9.13|$ & & & & 0.371 & 1.579 & $0.580-4.300$ \\
\hline Unknow & $98.0 \pm 38.632$ & & & & 0.562 & 1.306 & $0.530-3.219$ \\
\hline Tumor size & & 0.002 & 1.09 & $1.032-1.151$ & 0.001 & & \\
\hline$\leq 4.9 \mathrm{~cm}$ & & & & & Reference & & \\
\hline$>4.9 \mathrm{~cm}$ & $144.0 \pm 6.978$ & & & & $<0.001$ & 1.268 & I.II0-I.450 \\
\hline Unknow & $158.0 \pm 6.046$ & & & & 0.267 & 1.075 & $0.946-1.220$ \\
\hline
\end{tabular}

glioma. Age is considered an important prognostic factor in glioma patients. ${ }^{8}$ Several studies have shown that the susceptible site, histopathology, prognosis, and some molecular markers of glioma also vary across the age groups. ${ }^{9,10}$ The recent studies tend to dismiss the differences between the age groups while focusing on either children or adults alone. ${ }^{11-15}$ A growing number of studies have demonstrated that glioma is more aggressive in elderly patients than in younger patients. As surgery and radiochemotherapy are less indicated for the aging, the prognosis of elderly patients may be very poor. ${ }^{16-18}$ It is noteworthy that the treatment regimens may be developed cautiously for children with glioma to minimize the adverse impact of radiotherapy on brain development and also the risk of tumor-induced neurological dysfunction. On the contrary, there may not be too many concerns of possible risks when developing treatment regimens for elderly patients. An active radiochemotherapy plan is generally preferred for elderly patients. ${ }^{19-23}$ Many researchers have been aware of the differences between children and adults, but the differences across various age groups are not generally analyzed and the influence of age on the prognosis of OG patients has not yet been investigated. Some studies ${ }^{12,14}$ compared the mortality between children and adult cohorts, and it was found that the mortality was significantly lower in children than in adults. It was hypothesized that the mortality of OG patients increased with age. Our study supported this viewpoint, as the univariate and multivariate analyses showed that both the allcause mortality and tumor-specific mortality increased noticeably with age in the seven age groups. Individualized treatments are recommended for $\mathrm{OG}$ patients to achieve better outcomes.

On univariate and multivariate analysis, we found that female gender was associated with a low all-cause mortality and tumor-specific mortality compared to male. However, the evidence regarding the effect of reproductive factors and hormones on glioma has not been well investigated. Recent studies indicated that patients who have received standard treatment (surgery, radiation, and TMZ) within GBM, females was associated with a better outcomes compared to male. Barone et $\mathrm{al}^{24}$ shown that estrogen increases the survival rate in the in situ model of GBM, and studies based on estradiol may be beneficial in the treatment of GBM. Li et $\mathrm{al}^{25}$ observed hypermethylation of estrogen receptor in GBMs, indicating that estrogen might be a protective factor. Tian et $\mathrm{al}^{26}$ suggested that estrogen might protect against GBM genesis and promote a more favorable biology once GBM develops. Moreover, $\mathrm{Yu}$ et $\mathrm{al}^{27}$ found that androgen receptor signaling could promote tumorigenesis of GBM in adult men by inhibiting TGF- $\beta$ (transforming growth factor $\beta$ ) receptor signaling. 
Table 3 Univariate and Multivariate Cox Regression Analysis of Factors Associated with CSS in the Training Set ( $n=5437)$

\begin{tabular}{|c|c|c|c|c|c|c|c|}
\hline \multirow[t]{2}{*}{ Variance } & \multirow[t]{2}{*}{ Median SurvivalıSD (Months) } & \multicolumn{3}{|c|}{ Univariate Analysis } & \multicolumn{3}{|c|}{ Multivariate Analysis } \\
\hline & & $P$ value & HR & $95 \% \mathrm{Cl}$ & $P$ value & HR & $95 \% \mathrm{Cl}$ \\
\hline Race & & 0.079 & 0.904 & $0.807-1.012$ & & & \\
\hline Black & 169.0 & & & & & & \\
\hline White & $|97.0 \pm| 2.72 \mid$ & & & & & & \\
\hline \multicolumn{8}{|l|}{ Asian or Pacific Islander } \\
\hline \multicolumn{8}{|l|}{ American Indian/Alaska Native } \\
\hline \multicolumn{8}{|l|}{ Unknow } \\
\hline Sex & & 0.001 & 0.847 & $0.770-0.933$ & & & \\
\hline Male & $|87.0 \pm 7.75|$ & & & & Reference & & \\
\hline Female & & & & & 0.001 & 0.844 & $0.766-0.929$ \\
\hline Age & & $<0.001$ & 1.471 & $1.418-1.525$ & $<0.001$ & & \\
\hline $0-17 y r s$ & & & & & Reference & & \\
\hline $18-30 y r s$ & & & & & $<0.001$ & 2.331 & $1.573-3.453$ \\
\hline $31-40 y r s$ & 217.0 & & & & $<0.001$ & 2.569 & $1.753-3.765$ \\
\hline $4 I-50 y r s$ & 207.0 & & & & $<0.001$ & 3.189 & $2.182-4.662$ \\
\hline $5 \mathrm{I}-60 \mathrm{yrs}$ & $155.0 \pm 12.020$ & & & & $<0.001$ & 4.687 & $3.203-6.857$ \\
\hline $6 I-74 y r s$ & $60.0 \pm 6.133$ & & & & $<0.001$ & 9.544 & $6.498-14.018$ \\
\hline$\geq 75 y r s$ & $23.0 \pm 6.548$ & & & & $<0.001$ & 17.668 & | I.447-27.27| \\
\hline Tumor site & & $<0.001$ & 1.088 & $1.070-1.106$ & $<0.001$ & & \\
\hline Frontal lobe & & & & & Reference & & \\
\hline Temporal lobe & 163.0 & & & & $<0.001$ & 1.697 & $1.494-1.926$ \\
\hline Parietal lobe & 193.0 & & & & $<0.001$ & 1.356 & $1.153-1.596$ \\
\hline Occipital lobe & & & & & 0.199 & 1.267 & $0.883-1.817$ \\
\hline Cerebellum & & & & & 0.963 & 0.983 & $0.465-2.078$ \\
\hline Brain stem & $157.0 \pm 97.542$ & & & & 0.039 & 2.226 & $1.042-4.755$ \\
\hline Ventricle & $127.0 \pm 63.393$ & & & & 0.006 & 2.527 & $1.305-4.894$ \\
\hline Overlapping lesion of brain & $125.0 \pm 10.074$ & & & & $<0.001$ & 1.677 & $1.431-1.966$ \\
\hline Others & $154.0 \pm 19.292$ & & & & $<0.001$ & 1.887 & $1.54 \mid-2.312$ \\
\hline Laterality & & $<0.001$ & 1.183 & $1.114-1.256$ & $<0.001$ & & \\
\hline Left & & & & & Reference & & \\
\hline Right & $217.0 \pm 21.092$ & & & & 0.300 & 1.067 & $0.944-1.207$ \\
\hline Unknow & $166.0 \pm 9.703$ & & & & $<0.001$ & 1.415 & $1.233-1.625$ \\
\hline Extend of surgery & & $<0.001$ & 1.192 & $1.136-1.252$ & 0.066 & & \\
\hline
\end{tabular}


Table 3 (Continued).

\begin{tabular}{|c|c|c|c|c|c|c|c|}
\hline \multirow[t]{2}{*}{ Variance } & \multirow[t]{2}{*}{ Median Survival \pm SD (Months) } & \multicolumn{3}{|c|}{ Univariate Analysis } & \multicolumn{3}{|c|}{ Multivariate Analysis } \\
\hline & & P value & HR & $95 \% \mathrm{Cl}$ & P value & HR & $95 \% \mathrm{Cl}$ \\
\hline Gross total resection & & & & & reference & & \\
\hline Subtotal resection & $184.0 \pm 7.852$ & & & & 0.011 & 1.168 & $1.036-1.317$ \\
\hline Unspecified & & & & & 0.982 & 0.995 & $0.662-1.497$ \\
\hline No surgery & $155.0 \pm 12.066$ & & & & $0.57 I$ & 0.720 & $0.23 I-2.243$ \\
\hline Surgery $(\mathbf{Y} / \mathbf{N})$ & & $<0.001$ & 1.423 & $1.266-1.600$ & 0.537 & & \\
\hline Yes & 213.0 & & & & Reference & & \\
\hline No & $|55.0 \pm 1| .689$ & & & & 0.269 & 1.900 & $0.609-5.926$ \\
\hline Unknow & 98.0 & & & & 0.563 & 1.338 & $0.499-3.590$ \\
\hline Tumor size & & 0.001 & 1.101 & $1.038-1.168$ & 0.001 & & \\
\hline$\leq 4.9 \mathrm{~cm}$ & & & & & Reference & & \\
\hline$>4.9 \mathrm{~cm}$ & 162.0 & & & & $<0.001$ & 1.303 & I.127-I.505 \\
\hline Unknow & 193.0 & & & & 0.337 & 1.070 & $0.932-1.229$ \\
\hline
\end{tabular}

However, the association of sex hormones with an increased $O S$ in female patients warrants further investigation.

Since the publication of the new WHO classification of glioma in 2006, growing importance has been attached to the molecular features of glioma. For example, the $\mathrm{OG}$ cannot be confirmed unless determination of IDH mutational status and $1 \mathrm{p} / 19 \mathrm{q}$ codeletion status. Besides, the IDH mutational status and $1 p / 19 q$ codeletion status are known to be closely related to the prognosis of patients. Many reports have demonstrated the close connections between biomarkers and age. ${ }^{28}$ For example, in breast cancer, age is closely related to tumor grading and EGFR and HER-2 expressions. ${ }^{29}$ However, no molecular detection data in OG patients are available from the SEER database. Therefore, we could not further investigate the influence of age on the OG-related biomarkers, which is one of the defects of the present study.

Maximal safe resection of the tumor is the first and foremost step in the combination therapy for glioma. However, for OG and its molecular subtypes, the influence of tumor resection (GTR vs STR) on the prognosis seems very mild. ${ }^{1,15}$ This phenomenon may be explained by the sensitivity of $\mathrm{OG}$ to radiochemotherapy and the growth inertia of OG. Since total resection of OG may not bring significant survival benefits, a radical surgery that may cause nerve function impairment is usually unnecessary. We arrived at a similar conclusion as above. In our study, various degrees of surgical resection and whether the patients received surgical resection at all had little impact on all-cause mortality and tumor-specific mortality. In addition, many scholars believe that radiochemotherapy should be delayed for OG patients, which is entirely different from the importance attached to radiochemotherapy in glioblastoma. This belief is based on the findings from several studies: postponing the start of radiochemotherapy does not influence the survival of OG patients. More importantly, radiochemotherapy may cause significant toxic and side effects, such as radiation necrosis. ${ }^{30-33}$

However, studies using population databases are not without inherent limitations, including the heterogeneity of clinical practice in participating centers. Furthermore, there is a lack of information on chemotherapeutic regimens, Karnofsky Performance Scale status, and other clinical variables in the SEER database. Additionally, the neurooncology community is largely defining oligodendroglioma based on the presence of genetic events such as isocitrate dehydrogenase mutations and $1 p 19 q$ loss. These information are not available in the current SEER database. Another limitation of the SEER data set is that the extent of resection is subjectively and there is no volumetric quantitation. Finally, survival studies, such as the one conducted here, fail to take into consideration nonsurvival 
A

Points

$\begin{array}{lllllllllll}0 & 10 & 20 & 30 & 40 & 50 & 60 & 70 & 80 & 90 & 100\end{array}$

Age

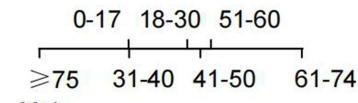

Sex

Male

Tumor site

Female

Temporal Frontal Ventricle Others

Laterality

Occipital Parietal Overlapping Brain stem Cerebellum

Tumor size

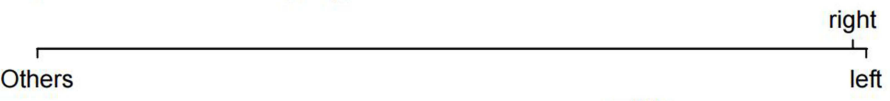

$<=4.9$

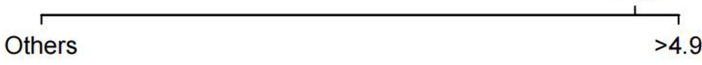

Total Points

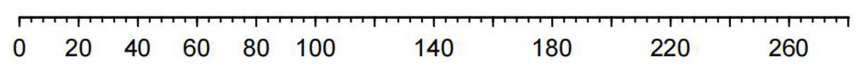

5-Year OS

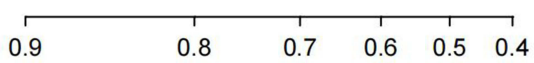

10-Year OS

$\begin{array}{lllllllll}0.9 & 0.8 & 0.7 & 0.6 & 0.5 & 0.4 & 0.3 & 0.2 & 0.1\end{array}$

15-Year OS

\begin{tabular}{lllllll}
\hline 0.7 & 0.6 & 0.5 & 0.4 & 0.3 & 0.2 & 0.1
\end{tabular}

B

Points

$\begin{array}{lllllllllll}0 & 10 & 20 & 30 & 40 & 50 & 60 & 70 & 80 & 90 & 100\end{array}$

Age

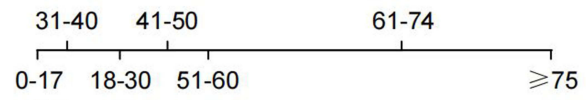

Sex

$$
\text { Male }
$$

Female

Tumor site

Temporal Frontal Ventricle Others

Laterality

Occipital Parietal Overlapping Cerebellum Brain stem

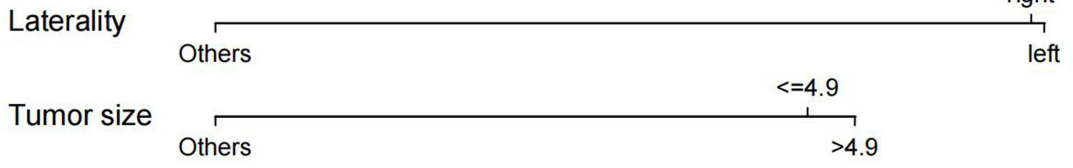

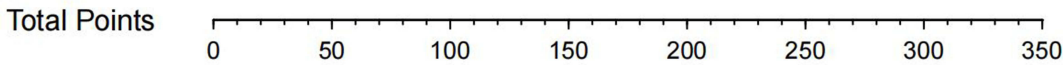

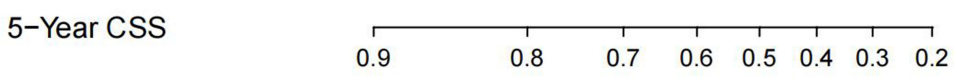

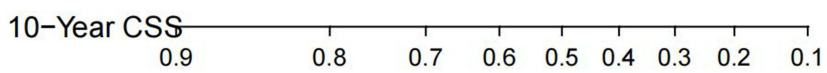

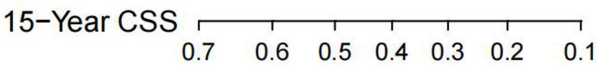

Figure 3 Nomogram for predicting OS and CSS of OG patients. (A) Nomogram for predicting 5-, 10- and 15-year OS of OG patients; (B) Nomogram for predicting 5-, 10and 15 -year CSS of OG patients. 
A

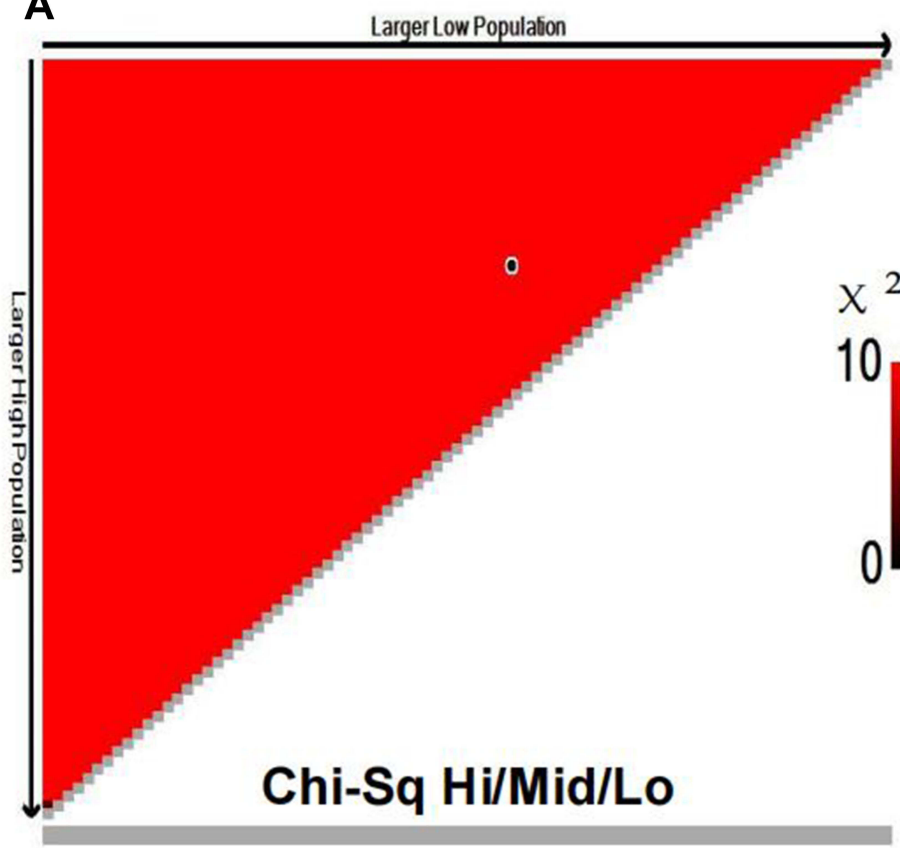

Chi-Sq Hi/Mid/Lo

B

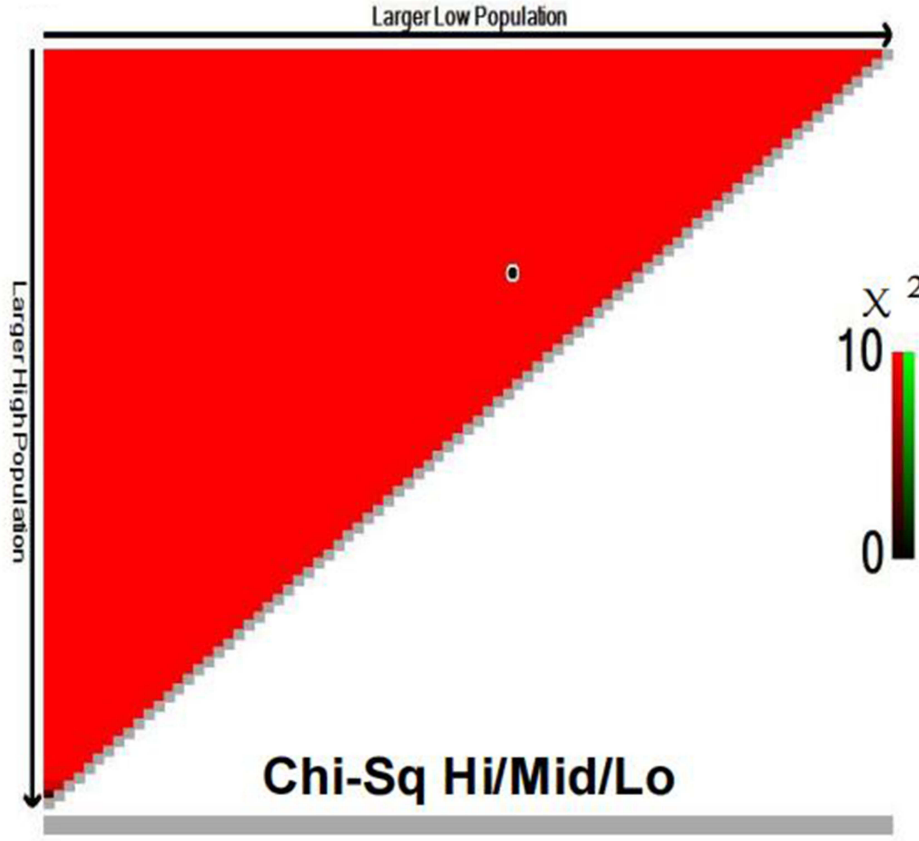

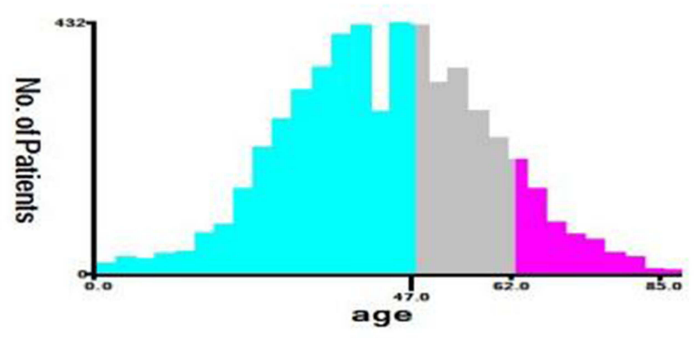

10
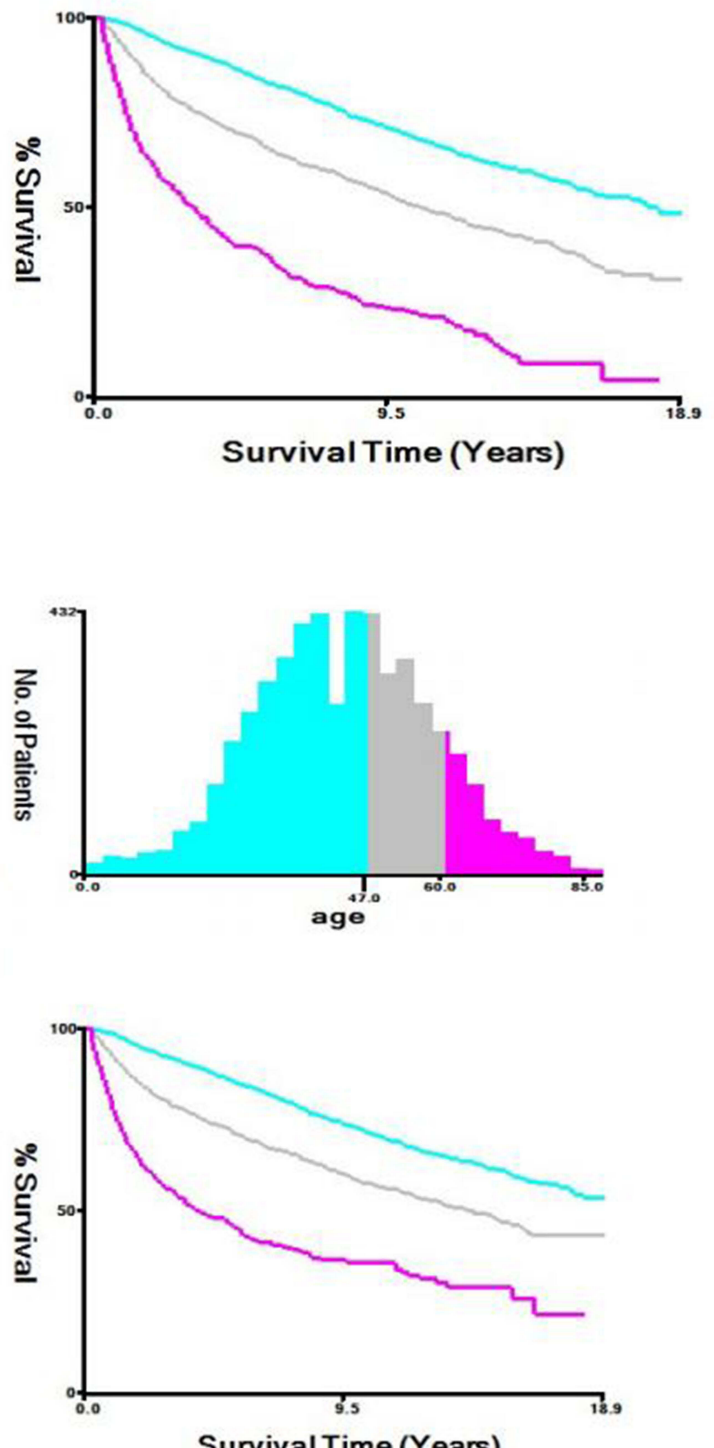

Figure 4 (A) Optimal cut-off point determined using X-tile software for OS; (B) Optimal cut-off point determined using X-tile software for CSS.

clinical benefits associated with extended resection of oligodendroglioma, such as reduction of seizure frequency, neurocognitive function, and quality of life.

\section{Conclusion}

The correlation between age and survival of OG patients was confirmed based on the SEER database. The older the 
age, the worse the survival would be. That's to say, the mortality increased with age. In the clinic, healthcare professionals should be fully aware of the variability in the prognosis of OG patients in different age groups. An individualized treatment is recommended for OG patients. It is not possible to distinguish oligodendrogliomas based on children, adults, and the elderly, but to develop diagnosis and treatment plans based on more detailed age groups.

\section{Abbreviations}

OG, oligodendroglioma; SEER, Surveillance, Epidemiology, and End Results; OS, overall survival; CSS, cause-specific survival; IDH, isocitrate dehydrogenase.

\section{Data Sharing Statement}

Data files were downloaded directly from the SEER website.

\section{Ethical Approval and Consent to Participate}

We signed the "Surveillance, Epidemiology, and End Results Program Data-Use Agreement" in accordance with the requirement of using SEER database. Therefore, we obtained the data using permission and could download data from the SEER database. The ethics committee of our hospital carries out its work in strict accordance with the Ethical Review of Biomedical Research Involving Human Beings, ICH-GCP, GCP and relevant regulations, etc., and performs the duties of biomedical research ethics review involved in human beings. The paper "Comparison of the prognosis of patients with oligodendroglioma in different age groups: an analysis based on the SEER population" does not belong to the scope of the ethics committee review and does not need to be reviewd according to the current ethical standards. The data on the paper is collected from public databases and belongs to public resources.

\section{Consent for Publication}

Each author satisfies the criteria for authorship. No individual person's data was applicable in this manuscript

\section{Acknowledgments}

I would like to express my gratitude to all those who have helped me during the writing of these thesis. I gratefully acknowledge the help of Professor Liang Xia. We acknowledge SEER*Stat team for providing patients' information.

\section{Author Contributions}

All authors contributed to data analysis, drafting or revising the article, gave final approval of the version to be published, agreed to the submitted journal, and agree to be accountable for all aspects of the work.

\section{Funding}

Youth Fund of the National Natural Science Foundation (81502147), Zhejiang Province Natural Science Foundation (LY21H160007, LQ21H160006), Youth Scientific Research Program of Zhejiang Cancer Hospital (QN201902). The funders had no role in study design, data collection and analysis, decision to publish, or preparation of the manuscript.

\section{Disclosure}

The authors declare that they have no competing interests.

\section{References}

1. Alattar AA, Brandel MG, Hirshman BR, et al. Oligodendroglioma resection: a Surveillance, Epidemiology, and End Results (SEER) analysis. J Neurosurg. 2018;128(4):1076-1083. doi:10.3171/2016.11.JNS161974

2. Lau CS, Mahendraraj K, Chamberlain RS. Oligodendrogliomas in pediatric and adult patients: an outcome-based study from the Surveillance, Epidemiology, and End Result database. Cancer Manag Res. 2017;9:159-166. doi:10.2147/CMAR.S117799

3. Shaw EG, Scheithauer BW, O'Fallon JR, Tazelaar HD, Davis DH. Oligodendrogliomas: the Mayo Clinic experience. J Neurosurg. 1992;76:428-434. doi:10.3171/jns.1992.76.3.0428

4. Louis DN, Perry A, Reifenberger G, et al. The 2016 World Health Organization classification of tumors of the central nervous system: a summary. Acta Neuropathol. 2016;131(6):803-820. doi:10.1007/ s00401-016-1545-1

5. Ogura R, Tsukamoto Y, Natsumeda M, et al. Immunohistochemical profiles of IDH1, MGMT and P53: practical significance for prognostication of patients with diffuse gliomas. Neuropathology. 2015;35 (4):324-335. doi:10.1111/neup.12196

6. Fanelli GN, Grassini D, Ortenzi V, et al. Decipher the glioblastoma microenvironment: the first milestone for new groundbreaking therapeutic strategies. Genes. 2021;12:443. doi:10.3390/genes12030445.

7. Bornhorst M. New insights into low grade glioma tumor microenvironment for improved patient management. Neuro Oncol. 2021: Noab224. doi:10.1093/neuonc/noab224

8. Jones C, Perryman L, Hargrave D. Paediatric and adult malignant glioma: close relatives or distant cousins? Nat Rev Clin Oncol. 2012;9(7):400-413. doi:10.1038/nrclinonc.2012.87

9. Bandopadhayay P, Bergthold G, London WB, et al. Long-term outcome of 4040 children diagnosed with pediatric low-grade gliomas: an analysis of the Surveillance Epidemiology and End Results (SEER) database. Pediatr Blood Cancer. 2014;61(7):1173-1179. doi:10.1002/pbc.24958

10. Qu HQ, Jacob K, Fatet S, et al. Genome-wide profiling using single-nucleotide polymorphism arrays identifies novel chromosomal imbalances in pediatric glioblastomas. Neuro Oncol. 2010;12 (2):153-163. doi:10.1093/neuonc/nop001

11. Furst T, Hoffman H, Chin LS. All-cause and tumor-specific mortality trends in geriatric oligodendroglioma (OG) patients: a surveillance, epidemiology, and end results (SEER) analysis. J Clin Neurosci. 2020;73:94-100. doi:10.1016/j.jocn.2020.01.022 
12. Wang KY, Vankov ER, Lin DDM. Predictors of clinical outcome in pediatric oligodendroglioma: meta-analysis of individual patient data and multiple imputation. J Neurosurg Pediatr. 2018;21(2):153-163. doi:10.3171/2017.7.PEDS17133

13. Lin DD, Deng XY, Zheng DD, et al. The effects of tumor size and postoperative radiotherapy for patients with adult low-grade (WHO grade II) infiltrative supratentorial astrocytoma/oligodendroglioma: a population-based and propensity score matched study. Cancer Med. 2018;7(12):5973-5987. doi:10.1002/cam4.1853

14. Goel NJ, Abdullah KG, Lang SS. Outcomes and prognostic factors in pediatric oligodendroglioma: a population-based study. Pediatr Neurosurg. 2018;53(1):24-35. doi:10.1159/000481458

15. Ding X, Wang Z, Chen D, et al. The prognostic value of maximal surgical resection is attenuated in oligodendroglioma subgroups of adult diffuse glioma: a multicenter retrospective study. J Neurooncol. 2018;140(3):591-603. doi:10.1007/s11060-018-2985-3

16. Krishnatry R, Zhukova N, Guerreiro Stucklin AS, et al. Clinical and treatment factors determining long-term outcomes for adult survivors of childhood low-grade glioma: a population-based study. Cancer. 2016;122(8):1261-1269. doi:10.1002/cncr.29907

17. Lowry JK, Snyder JJ, Lowry PW. Brain tumors in the elderly: recent trends in a Minnesota cohort study. Arch Neurol. 1998;55 (7):922-928. doi:10.1001/archneur.55.7.922

18. Perry JR, Laperriere N, O'Callaghan CJ, et al. Short-course radiation plus temozolomide in elderly patients with glioblastoma. $N$ Engl J Med. 2017;376(11):1027-1037. doi:10.1056/NEJMoa1611977

19. Indelicato DJ, Rotondo RL, Uezono H, et al. Outcomes following proton therapy for pediatric low-grade glioma. Int $J$ Radiat Oncol Biol Phys. 2019;104(1):149-156. doi:10.1016/j.ijrobp.2019.01.078

20. Yamaguchi F. Therapy decisions for patients with high-grade glioma and their families. World Neurosurg. 2017;102:671-672. doi:10.1016/j.wneu.2017.03.094

21. Marra JS, Mendes GP, Yoshinari GH Jr, da Silva Guimaraes F, Mazin SC, de Oliveira HF. Survival after radiation therapy for high-grade glioma. Rep Pract Oncol Radiother. 2019;24(1):35-40. doi:10.1016/j.rpor.2018.09.003

22. Badiyan SN, Ulmer S, Ahlhelm FJ, et al. Clinical and radiologic outcomes in adults and children treated with pencil-beam scanning proton therapy for low-grade glioma. Int J Part Ther. 2017;3 (4):450-460. doi:10.14338/IJPT-16-00031.1
23. Bitterman DS, MacDonald SM, Yock TI, et al. Revisiting the role of radiation therapy for pediatric low-grade glioma. J Clin Oncol. 2019;37(35):3335-3339. doi:10.1200/JCO.19.01270

24. Barone TA, Gorski JW, Greenberg SJ, Plunkett RJ. Estrogen increases survival in an orthotopic model of glioblastoma. $J$ Neurooncol. 2009;95(1):37-48. doi:10.1007/s11060-009-9904-6

25. Li Q, Jedlicka A, Ahuja N, et al. Concordant methylation of the ER and N33 genes in glioblastoma multiforme. Oncogene. 1998;16 (24):3197-3202. doi:10.1038/sj.onc.1201831

26. Tian M, Ma W, Chen Y, et al. Impact of gender on the survival of patients with glioblastoma. Biosci Rep. 2018:38. doi:10.1042/ BSR20180752

27. Yu X, Jiang Y, Wei W, et al. Androgen receptor signaling regulates growth of glioblastoma multiforme in men. Tumour Biol. 2015;36:967-972. doi:10.1007/s13277-014-2709-Z

28. Thewjitcharoen Y, Krittiyawong S, Butadej S, et al. Dedifferentiation of papillary thyroid carcinoma into squamous cell carcinoma in an elderly patient: a case report. Medicine. 2020;99: e19892. doi:10.1097/MD.0000000000019892

29. Ito Y, Takeda T, Sakon M, et al. Expression and clinical significance of erb-B receptor family in hepatocellular carcinoma. Br J Cancer. 2001;84:1377-1383. doi:10.1054/bjoc.2000.1580

30. Olson JD, Riedel E, DeAngelis LM. Long-term outcome of low-grade oligodendroglioma and mixed glioma. Neurology. 2000;54(7):1442-1448. doi:10.1212/wnl.54.7.1442

31. van den Bent MJ, Afra D, de Witte O, et al. Long-term efficacy of early versus delayed radiotherapy for low-grade astrocytoma and oligodendroglioma in adults: the EORTC 22845 randomised trial. Lancet. 2005;366(9490):985-990. doi:10.1016/S0140-6736(05) 67070-5

32. Roth P, Wick W, Weller M. Anaplastic oligodendroglioma: a new treatment paradigm and current controversies. Curr Treat Options Oncol. 2013;14(4):505-513. doi:10.1007/s11864-013-0251-7

33. Ahmad H, Martin D, Patel SH, et al. Oligodendroglioma confers higher risk of radiation necrosis. $J$ Neurooncol. 2019;145 (2):309-319. doi:10.1007/s11060-019-03297-7
International Journal of General Medicine

\section{Publish your work in this journal}

The International Journal of General Medicine is an international, peer-reviewed open-access journal that focuses on general and internal medicine, pathogenesis, epidemiology, diagnosis, monitoring and treatment protocols. The journal is characterized by the rapid reporting of reviews, original research and clinical studies across all disease areas. The manuscript management system is completely online and includes a very quick and fair peer-review system, which is all easy to use. Visit http://www.dovepress.com/ testimonials.php to read real quotes from published authors. 